\title{
Direct Parastomal Percutaneous Embolization for Bleeding Stomal Varices
}

\author{
Manu K. Singh ${ }^{1} \quad$ Stuart E. Braverman ${ }^{1} \quad$ Steve Hartzman ${ }^{1} \quad$ Arthur Lee $^{1}$ \\ ${ }^{1}$ Department of Interventional Radiology, Santa Barbara \\ Cottage Hospital, Santa Barbara, California, United States \\ Address for correspondence Manu K. Singh, MD, Santa Barbara \\ Cottage Hospital, Santa Barbara, CA, United States \\ (e-mail: manukushsingh@gmail.com).
}

\begin{abstract}
Keywords

- cirrhosis

- parastomal percutaneous embolization

- peristomal varices

- variceal embolization

- varices

A 71-year-old woman with a history of colon cancer and nonalcoholic fatty liver disease presented with lower gastrointestinal $(\mathrm{Gl})$ bleeding. Workup revealed cirrhosis with peristomal varices, which was managed successfully with computed tomography (CT)-guided percutaneous parastomal access and subsequent embolization.
\end{abstract}

\section{Images in IR}

A 71-year-old woman postcolostomy for colorectal cancer 20 years ago presented with multiple hospital admissions for lower gastrointestinal (GI) bleeding. Her medical history was significant for nonalcoholic cirrhosis resulting from fatty infiltration of the liver. After multiple negative colonoscopies, the source of bleeding was suggested at the mucosa of the ostomy site, which was unsuccessfully treated with silver nitrate. A computed tomographic (CT) scan was performed, which demonstrated evidence of cirrhosis with prominent peristomal varices ( - Fig. 1A, arrow) supplied by a large col-

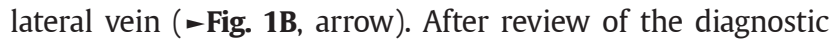
imaging, it was thought that percutaneous access with CT guidance might allow for optimal access. Under CT guidance, the large collateral vein was identified and accessed with a 21-gauge needle from an anterior approach adjacent to the stoma allowing for guidewire placement ( - Fig. 2). The patient was then transferred to the angiography suite. Through a microintroducer sheath, a microcatheter was advanced to the portal venous system. Injection of the accessed collateral
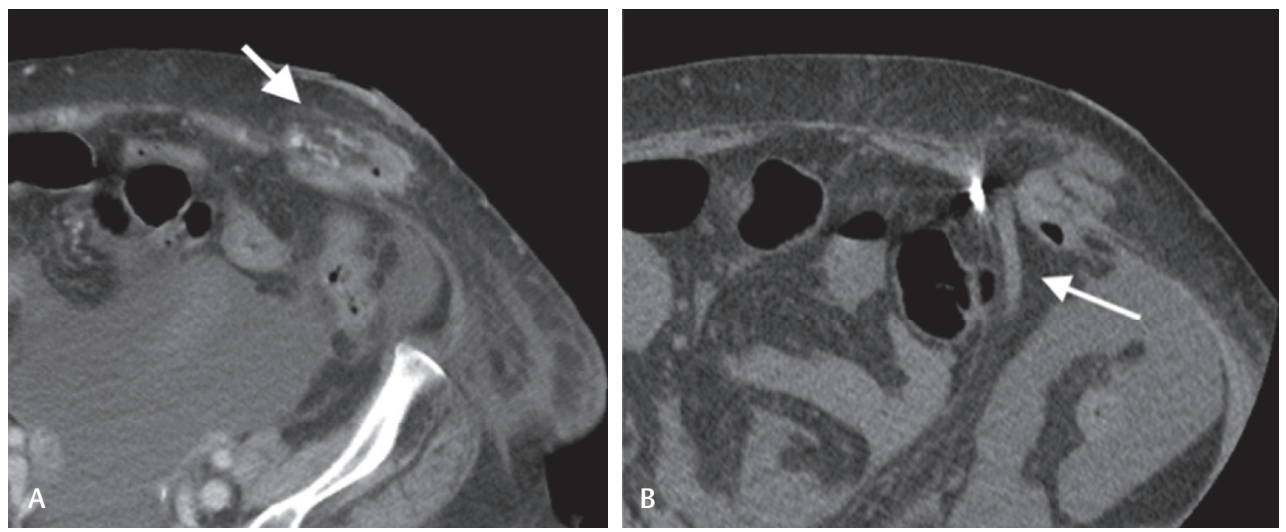

Fig. 1 Stomal varices (A, arrow) supplied by a large collateral varix in the left lower quadrant (B, arrow).

received

April 28, 2017

accepted after revision

September 27, 2017

published online

June 20, 2018
DOI https://doi.org/

10.1055/s-0038-1641675.

ISSN 2457-0214.
Copyright $\odot 2018$ by Indian Society of Vascular and Interventional Radiology
License terms

(c) (1) $\ominus \circledast$ 


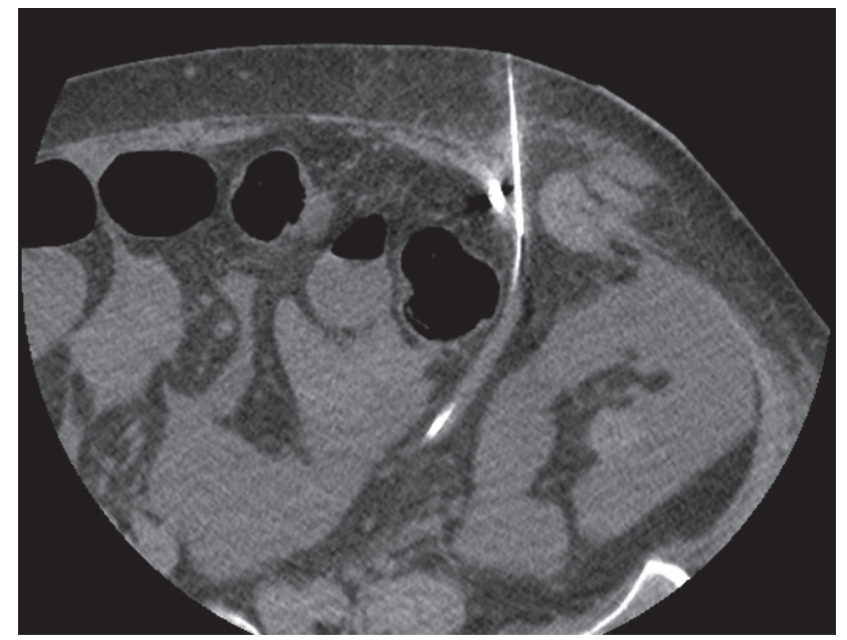

Fig. 2 CT-guided percutaneous access of the large collateral supplying the parastomal varices.

below at its confluence with the splenic vein demonstrated retrograde flow toward the left lower quadrant stoma opacifying peristomal collaterals. Embolization was then performed using microcoils ( - Fig. 3, arrow), across a channel of tangle of collateral vessels; Gelfoam slurry was then injected in the

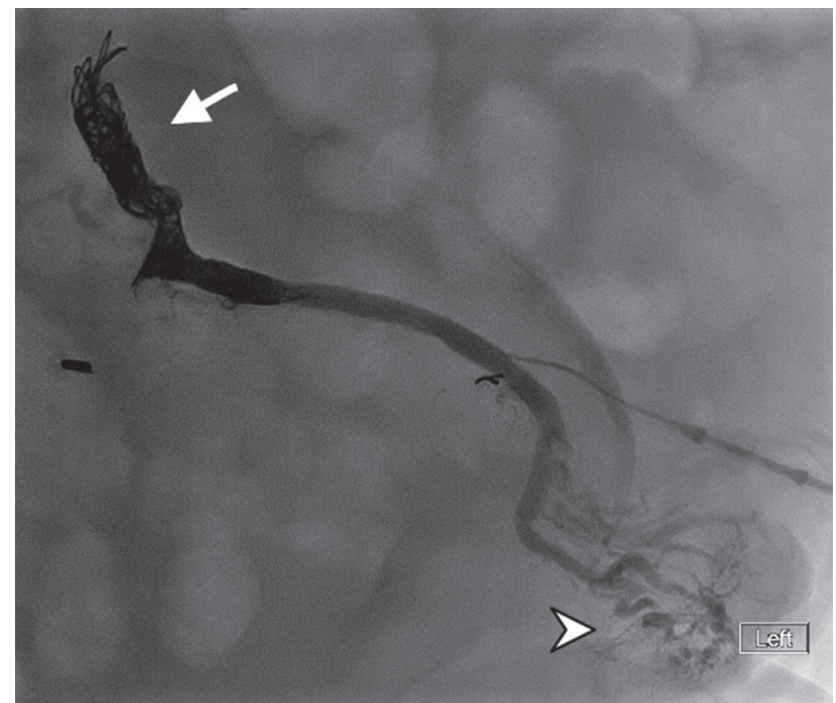

Fig. 3 After coil embolization (arrows), Gelfoam slurry was then injected, which flowed to the peristomal varices (arrowhead).

most peripheral segment with flow to the peristomal varices achieving stasis ( - Fig. 3, arrowhead). The patient's hemoglobin stabilized and without further episodes of stomal bleeding upon discharge and at 6-week follow-up. 